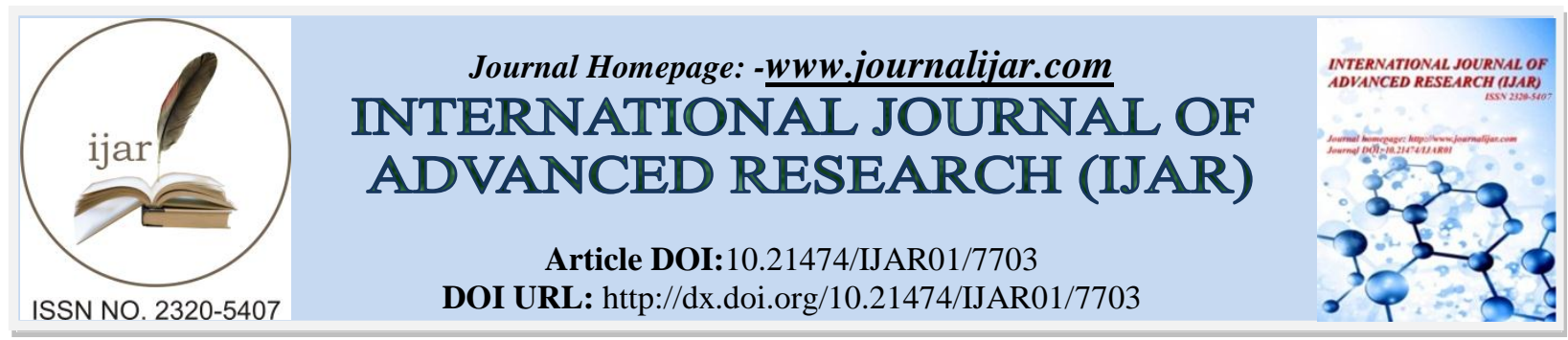

RESEARCH ARTICLE

\title{
MATERNAL CHRONIC DISEASES AS RISK FACTOR OF CYANOTIC HEART DEFECTS (FALLOT TETRALOGY \& PDA) AMONG CHILDREN IN MALLAWY CITY.
}

Khaled Hussein M.I. El dessouki and Mohamed Ahmed Bahaa el-deen.

1. Department of Public health and preventive medicine, Faculty of Medicine, Minia University, Egypt.

2. Department of Pediatrics, Faculty of Medicine, Minia University, Egypt.

\section{Manuscript Info}

Manuscript History

Received: 20 July 2018

Final Accepted: 26 August 2018

Published: September 2018

Keywords:-

cyanotic, congenital heart defects (CHD), maternal chronic diseases, risk factors.

\begin{abstract}
Information about known risk factors for cyanotic congenital heart defects is deficient. This study aimed to investigate the relationship between maternal chronic disease and cyanotic congenital heart disease in offspring. Cyanotic congenital heart defects (CHDs) are associated with multiple risk factors such as maternal febrile illness, maternal Hypertension (HTN), Diabetes Mellitus (DM), SLE, Epilepsy, and birth weight of the child. The current study was aimed to study the relationship between some maternal chronic diseases and the development of common cyanotic congenital heart defects. A crosssectional study was done on patients attending the pediatric outpatient clinic in Mallawy general hospital from October 2016 to April 2017. A total of 100 patients were included in the study. It was found that the most 2 common types of cyanotic congenital heart diseases were PDA and Fallot tetralogy there was a positive significant association $(\mathrm{p}<0.05)$ between ( maternal DM, maternal HTN, maternal infection and maternal history of receiving medications) and occurrence of cyanotic CHD
\end{abstract}

Copy Right, IJAR, 2018, All rights reserved.

\section{Introduction:-}

A cyanotic heart defect is a group-type of congenital heart defect (CHD) that occurs due to deoxygenated blood bypassing the lungs and entering the systemic circulation or a mixture of oxygenated and unoxygenated blood entering the systemic circulation. It is caused by structural defects of the heart (i.e.: right-to-left, bidirectional shunting, malposition of the great arteries), or any condition which increases pulmonary vascular resistance. The result is the development of collateral circulation.

\section{Signs and symptoms}

1. Clubbing

2. The patient assuming a crouching position

3. Cyanosis - facial discoloration (particularly the lips) and digit discoloration (fingers \& toes).

4. Crying

5. Crabbiness/irritability

6. Tachycardia

7. Tachypnea

8. A history of inadequate feeding. 
9. Unusually large toe \& fingernails.

10. Delayed development (both biological \& psychological).

\section{Types of cyanotic, congenital heart defects}

1. Tetralogy of Fallot.

2. Total anomalous pulmonary venous connection

3. Hypoplastic left heart syndrome (HLHS)

4. Transposition of the great arteries (d-TGA)

5. Truncus arteriosus (Persistent)

6. Tricuspid atresia

7. Interrupted aortic arch

8. Pulmonary atresia (PA)

9. Pulmonary stenosis (critical)

10. Eisenmenger syndrome (reversal of shunt due to pulmonary hypertension).

11. Patent ductus arteriosus.

The most common types of cyanotic congenital heart diseases were PDA and then Fallot tetralogy (Elizabeth et al 2008)

As stated by a study on cyanotic congenital heart disease (CCHD) in Sohag University. 50 neonates were diagnosed as suffering from cyanotic congenital heart disease (CCHD), they concluded that cyanotic congenital heart disease (CCHD) frequency was significant $(9.5 \%)$ with D-TGA being the commonest type. Majority of neonates with Cyanotic congenital heart disease (CCHD) showed survival with suitable management. (Abou-Taleb et al 2016)

Congenital heart diseases (CHDs) are the most common types of birth defects among live births (CDC, 2016). (CHDs) represent one of the most prevalent malformations among live births and remain the leading cause of death from congenital malformations (Botto et al., 2003).

The prevalence of CHD in Egypt was 1/1000 live birth (Bassilli et al., 2000) Recently congenital heart diseases (CHD) affect 1-2\% of newborn children in Egypt in 2016 and are the leading cause of death in infants under 1 year of age (Mazen et al., 2016).

Congenital heart diseases (CHDs) are responsible for the largest proportion (30-50\%) of mortality caused by birth defects in a pediatric age in Egypt (Atwa and Safar, 2014).

Types of CHD are atrial septal defect (ASD), ventricular septal defect (VSD), atrioventricular septal defect (AVSD), aortic stenosis (AS), pulmonary stenosis (PS), coarctation of aorta (Coarc), bicuspid aortic valve(BAV), double outlet right ventricle (DORV), single ventricle(SV) and patent ductus arteriosus (PDA) (Hoffman and Kaplan, 2002).

The risk factors of cyanotic CHD are maternal febrile illness, maternal history of Diabetes mellitus (DM), Hypertension(HTN), Systemic Lupus Erythematosus(SLE), Epilepsy, maternal cigarette smoking, maternal caffeine intake ,maternal receiving medication during pregnancy (Jenkins et al., 2007), socio-economic status of the family and paternal residence, family inherited disease history and birth weight of child <2500 grams (Tandon et al., 2010).

Consanguinity was significantly associated with a ventricular septal defect (VSD), atrial septal defect (ASD), atrioventricular septal defect (AVSD), pulmonary stenosis (PS), and pulmonary atresia (PA). There was no relationship between consanguinity and tetralogy of Fallot (TOF), tricuspid atresia (TA), aortic stenosis (AS), coarctation of the aorta (Coarc), and patent ductus arteriosus (PDA) (Becker and Al-Halees, 2001).

\section{The aim of the study:-}

This study was conducted to identify the relationship between maternal chronic diseases and development of cyanotic congenital heart diseases. 


\section{Methods:-}

\section{Study design and population:}

The cross-sectional hospital-based study was done on All cyanotic congenital heart defects patients attending the pediatric outpatient clinic in Mallawy general hospital from October 2016 to April 2017. A total of 100 patients were included in the study. in the age group of 1 week to 18 years. Pediatric patients include neonates (birth to 1 month), infants ( 1 month to 2 years), children ( 2 to 12 years) and adolescents younger than 18 years old. The study was conducted to assess the relation between cyanotic congenital heart defects and Maternal past history of (Diabetes, Hypertension, cardiac disease, SLE, infection during pregnancy (fever), obesity, history of receiving medication during pregnancy.......etc.).

\section{Ethical considerations:}

The study was approved by the Department of Public Health and Preventive Medicine and ethical committee of the Faculty of Medicine, Minia University. Before data collection, a verbal consent was obtained from all parents' of CHD patients after supplying comprehensive information about the nature and objectives of the study.

\section{Data collection:}

Data were collected by using a constructed questionnaire asking about risk factors of cyanotic CHD and it was applied to patient's parents attending the pediatric outpatient clinic in Mallawy general hospital from October 2016 to April 2017. The questionnaire included: Personal history, Type of cyanotic CHD, Risk factors of CHDs, maternal chronic diseases, Follow up and Complications

\section{Inclusion criteria:}

All cyanotic congenital heart defects patients attending the pediatric outpatient clinic in Mallawy general hospital from October 2016 to April 2017. aged (1week -18 years).

\section{Exclusion criteria:}

Neonate with cyanotic congenital heart disease less than 1 week, Patient with cyanotic congenital heart disease more than 18 years, Pediatric patients with CHD who follow up in the outpatient clinic without their parents, Pediatric patients with heart disease other than cyanotic congenital heart disease.

\section{Data analysis:}

After completing the study, the data from the questionnaires were gathered and statistically analyzed using SPSS, version 19.

\section{Results:-}

This study shows that most of the maternal and paternal educations at a level before university, more than $50 \%$ of them are illiterate while only less than (10\%) have education till university or above. About $82 \%$ of paternal occupations are manual workers; more than $90 \%$ of mothers are housewives. More than $90 \%$ of families' income was less than 2000 pounds per month. So they are of low social class as shown in (Table 1).

Total cases of cyanotic CHD were 100 this table shows that only (7\%) of mothers of children with CHD have a history of DM before pregnancy, (23\%) of mothers have a history of HTN (20\% gestational and 3\% before pregnancy). only $3 \%$ of mothers have toxoplasmosis, $6 \%$ of them have the hepatitis $\mathrm{C}$ virus. About $30 \%$ of mothers have a history of maternal infection during pregnancy (Table 2).

The present study shows that (79\%) of diabetic mothers have children with CHD and (21\%) of non-diabetic mothers have children with cyanotic CHD. The difference between diabetic mothers and non-diabetic mothers regarding the types of CHD is statistically significant $(\mathrm{P}=0.03)$. (Table 3 ).

Table 4 shows that (75\%) of hypertensive mothers have children with cyanotic CHD compared to (25\%) of nonhypertensive mothers have children with cyanotic CHD, the difference between hypertensive mothers and nonhypertensive mothers regarding the types of CHD is statistically significant $(\mathrm{P}=0.01)$. 
We found that (67\%) of mothers of cases have a fever during pregnancy compared to (33\%) of mothers of cases have no history of maternal infection during pregnancy, the difference between maternal infection during pregnancy and not regarding the types of CHD is statistically significant $(\mathrm{P}=0.0001)$ (Table 5).

Our study results show that the most important risk factors for developing a child with PDA were a maternal history of receiving medication maternal HTN, maternal obesity, maternal DM, maternal infection and maternal history of coffee, tea or coke intake. The odds ratio was respectively maternal receiving medication 26 , maternal HTN 15.5 , maternal obesity 9, maternal DM 6, maternal infection 5 and maternal history of coffee, tea or coke intake 2.8 . (Table 6). The most important risk factor for developing a child with Fallot tetralogy was maternal HTN. The odds ratio was 15.5. (Table 7).

Table 1:-Socio-economic characteristics of patients with cyanotic CHD patients attending the pediatric outpatient clinic in Mallawy general hospital from October 2016 to April 2017:

\begin{tabular}{|c|c|c|c|}
\hline \multicolumn{2}{|c|}{ Socio-economic characteristics } & Number & Percentage \\
\hline \multirow{4}{*}{ Paternal education: } & -Illiterate & 55 & $55 \%$ \\
\hline & -Read and write & 6 & $6 \%$ \\
\hline & -Intermediate education & 36 & $36 \%$ \\
\hline & -University and above & 3 & $3 \%$ \\
\hline \multirow{4}{*}{ Maternal education: } & -Illiterate & 60 & $60 \%$ \\
\hline & -Read and write & 10 & $10 \%$ \\
\hline & -Intermediate education & 25 & $25 \%$ \\
\hline & -University and above & 5 & $5 \%$ \\
\hline \multirow{4}{*}{ Paternal occupation: } & -Unemployed & 1 & $1 \%$ \\
\hline & -Employee & 9 & $9 \%$ \\
\hline & -Manual & 81 & $81 \%$ \\
\hline & -Professional & 9 & $9 \%$ \\
\hline \multirow[b]{2}{*}{ Maternal occupation: } & -Housewife & 94 & $94 \%$ \\
\hline & -Working mothers & 6 & $6 \%$ \\
\hline \multirow{3}{*}{ Income/month: } & $<1000$ & 39 & $39 \%$ \\
\hline & $1000-2000$ & 53 & $53 \%$ \\
\hline & $>2000$ & 8 & $8 \%$ \\
\hline
\end{tabular}

Table 2:-Frequency distribution of maternal past history of health problems as risk factors for developing cyanotic congenital heart diseases among patients attending the pediatric outpatient clinic in Mallawy general hospital from October 2016 to April 2017:

\begin{tabular}{|l|l|l|}
\hline Past history of maternal diseases & Number & Percentage \\
\hline Maternal Diabetes & 7 & $7 \%$ \\
\hline Gestational DM & 0 & $0 \%$ \\
\hline Maternal Hypertension & 3 & $3 \%$ \\
\hline Gestational HTN & 20 & $20 \%$ \\
\hline Maternal Epilepsy & 0 & $0 \%$ \\
\hline Maternal cardiac diseases & 0 & $0 \%$ \\
\hline Maternal Systemic Lupus Erythematosus & 1 & $1 \%$ \\
\hline Maternal Toxoplasmosis & 3 & $3 \%$ \\
\hline Maternal HCV & 6 & $6 \%$ \\
\hline Maternal infection during pregnancy & $30 \%$ \\
\hline Mothers who do not have any disease & 30 & $30 \%$ \\
\hline Total & 100 & $100 \%$ \\
\hline
\end{tabular}


Table 3:-Diabetic mothers as risk factors for developing cyanotic congenital heart diseases among patients attending the pediatric outpatient clinic in Mallawy general hospital from October 2016 to April 2017:

\begin{tabular}{|l|l|l|l|l|}
\hline \multirow{2}{*}{ Congenital Heart Diseases } & \multicolumn{2}{|l|}{ Diabetic Mothers } & \multicolumn{2}{l|}{ Nondiabetic mothers } \\
\cline { 2 - 5 } & NO & Percent & NO & Percent \\
\hline PDA & 40 & $40 \%$ & 10 & $10 \%$ \\
\hline Fallot tetralogy & 39 & $39 \%$ & 11 & $11 \%$ \\
\hline Total=100 (100\%) & 79 & $79 \%$ & 21 & $21 \%$ \\
\hline P value & 0.03 & \multicolumn{3}{|l}{} \\
\hline
\end{tabular}

Table 4:-Effect of hypertensive mothers on developing cyanotic congenital heart diseases among patients attending the pediatric outpatient clinic in Mallawy general hospital from October 2016 to April 2017:

\begin{tabular}{|l|l|l|l|l|}
\hline \multirow{2}{*}{ Congenital Heart Diseases } & \multicolumn{2}{|l|}{} \\
\cline { 2 - 5 } & Hypertensive mothers & \multicolumn{2}{l|}{ Nonhypertensive mothers } \\
\cline { 2 - 5 } & NO & Percent & NO & Percent \\
\hline PDA & 35 & $35 \%$ & 15 & $15 \%$ \\
\hline Fallot tetralogy & 40 & $40 \%$ & 10 & $10 \%$ \\
\hline Total $=100(100 \%)$ & 75 & $75 \%$ & 25 & $25 \%$ \\
\hline P value & 0.01 & \multicolumn{2}{|l}{} \\
\hline
\end{tabular}

Table 5:-Maternal infection during pregnancy as a risk factor for developing cyanotic congenital heart diseases among patients attending the pediatric outpatient clinic in Mallawy general hospital from October 2016 to April 2017:

\begin{tabular}{|c|c|c|c|c|}
\hline \multirow{2}{*}{ Congenital Heart Diseases } & \multicolumn{2}{|c|}{ Maternal infection } & \multicolumn{2}{|c|}{ No infection } \\
\hline & $\mathrm{NO}$ & Percent & $\mathrm{NO}$ & Percent \\
\hline PDA & 33 & $33 \%$ & 17 & $17 \%$ \\
\hline Fallot tetralogy & 34 & $34 \%$ & 16 & $16 \%$ \\
\hline Total $=220(100 \%)$ & 67 & $67 \%$ & 33 & $33 \%$ \\
\hline $\mathrm{P}$ value & \multicolumn{4}{|c|}{0.00001} \\
\hline
\end{tabular}

Table 6:-Logistic regression analysis for most important risk factors for developing a child with PDA among on cyanotic congenital heart defects patients attending the pediatric outpatient clinic in Mallawy general hospital from October 2016 to April 2017:

\begin{tabular}{|l|l|l|}
\hline Risk factors for developing a child with PDA: & $\mathbf{O . R}^{*}(\mathbf{C . I})^{* *}$ & P value \\
\hline Maternal history of receiving medication: & $26(4.5-149)$ & 0.0001 \\
\hline -Maternal HTN & $15.5(4-58.5)$ & 0.0001 \\
\hline -Maternal obesity & $9(4-22)$ & 0.0001 \\
\hline -Maternal DM & $6(1.5-26.5)$ & 0.01 \\
\hline -Maternal infection & $5(1-24.5)$ & 0.04 \\
\hline Maternal history of coffee, tea or coke intake: & $2.8(1-7)$ & 0.02 \\
\hline Consanguinity: & $1.4(.5-3.6)$ & 0.5 \\
\hline Passive cigarette smoking: & $1.6(.7-3.8)$ & 0.2 \\
\hline O.R* ${ }^{*}=$ Odds ratio &
\end{tabular}
O.R* $=$ Odds ratio
C.I**= Confidence interval.

Table 7:-Logistic regression analysis for most important risk factors for developing a child with Fallot tetralogy among on cyanotic congenital heart defects patients attending the pediatric outpatient clinic in Mallawy general hospital from October 2016 to April 2017:

\begin{tabular}{|l|l|l|}
\hline Risk factors for developing a child with Fallot tetralogy: & \multicolumn{1}{|c|}{ O.R* (C.I)** $^{* *}$} & P value \\
\hline -Maternal HTN & $15.5(4-63.5)$ & 0.00001 \\
\hline -Cigarette smoking: & $2.5(00)$ & 1 \\
\hline
\end{tabular}




\begin{tabular}{|l|l|l|}
\hline -Shisha smoking : & $0.000(000)$ & 0.99 \\
\hline -Maternal history of receiving medication: & $0.000(000)$ & 0.99 \\
\hline -Maternal DM & $0.000(000)$ & 0.99 \\
\hline -Maternal infection & $0.000(00)$ & 0.99 \\
\hline -Maternal obesity & $1.5(.4-6)$ & 0.5 \\
\hline
\end{tabular}

O.R $*=$ Odds ratio C.I**= Confidence interval.

\section{Discussion:-}

The present study has been conducted to identify the effect of the maternal chronic diseases as possible risk factors for cyanotic congenital heart diseases in Mallawy city Minia governorate (Webb et al., 2011).

From this study it was founded that the most 2 common types of cyanotic congenital heart diseases was PDA, and Fallot tetralogy which was in agreement with (Faheem et al., 2011) in Karachi, Pakistan, who revealed that the most common cardiovascular anomalies were VSD 39\% followed by ASD, PDA and Fallot tetralogy. Our study found different results of a study by (Khalid et al., 2006) in Beirut, Lebanon, who stated that the most common cardiovascular malformation was VSD followed by ASD. On the other hand (Tandon et al., 2010) in their study revealed that the most common type of CHD was ASD followed by VSD, Fallot tetralogy, and PDA. This difference may be due to the different sample size.

The most important risk factors for developing child with PDA: From our study it was found by logistic regression (Table 4) that the most important risk factor for developing child with PDA was maternal receiving medication $(\mathrm{p}=0.0001)$ odds $(26)$ followed by maternal HTN ( $\mathrm{p}=0.0001)$ odds $(15.5)$, maternal obesity ( $\mathrm{p}=0.0001)$ odds (9), maternal DM ( $\mathrm{p}=0.01$ ) odds (6), maternal infection ( $\mathrm{p}=0.04)$ odds (5) and maternal caffeine intake $(\mathrm{p}=0.02)$ odds (2.8). Which in agreement with (Caton et al., 2009) in USA who found that there was positive significant $(\mathrm{p}<0.001)$ association between maternal HTN and occurrence of PDA, This is in agreement with (Blomberg and Kallen, 2010) in Sweden who identified that there is a positive significant association between excess weight among potential mothers and the development of CHD and the strong association between maternal obesity and development PDA. (Banhidy et al., 2010) also, agree with our study in founding that DM has been associated with PDA. In agreement with our results (Tandon et al., 2010) identified that there was a positive significant association $(\mathrm{p}<0.05)$ between maternal infection and PDA.

The most important risk factors for developing a child with Fallot tetralogy: Our study revealed by logistic regression (Table 5) that the most important risk factor for developing a child with Fallot was maternal hypertension $(\mathrm{p}=0.00001)$ odds ratio (15.5). This is in agreement with (Caton et al., 2009) in USA who found positive significant $(\mathrm{p}<0.001)$ association between maternal HTN and occurrence of Fallot tetralogy

\section{Conclusion:-}

The most common type of cyanotic congenital heart diseases was PDA, followed by Fallot tetralogy. There was a positive significant association $(\mathrm{p}<0.05)$ between (consanguinity, maternal DM, maternal HTN, maternal infection, maternal smoking, maternal caffeine intake, maternal history of receiving medications and low birth weight) and occurrence of cyanotic CHD. 


\section{References:-}

1. Abou-Taleb, A., Abdelhamid, M. A., \& Bahkeet, M. A. (2016). Clinical profile of cyanotic congenital heart disease in the neonatal intensive care unit at Sohag University Hospital, Upper Egypt. Egyptian Journal of Medical Human Genetics.

2. Alverson CJ, Strickland MJ, Gilboa SM, and Correa A. Maternal smoking and congenital heart defects in the Baltimore- Washington Infant Study. Pediatrics 2011; 127:647-653.

3. Atwa ZT and Safar HH. The outcome of congenital heart diseases in Egyptian children. Egyptian Pediatric Association Gazette 2014; 62(2): 35-40.

4. Banhidy F, Acs N, Puho EH, and Czeizel AE. Congenital abnormalities in the offspring of pregnant women with type 1, type 2, and gestational diabetes mellitus: a population based case-control study. Congenit Anom Kyoto 2010; 50:115-121.

5. Bassili A, Mokhtar SA, Dabous NI, Zaher SR, Mokhtar MM and Zaki A. Congenital heart disease among school children in Alexandria, Egypt: An overview of prevalence and relative frequencies. J Trop Pediatr.2000; 46:357-362.

6. Becker SM, Al Halees Z, Molina C, and Paterson RM. Consanguinity and congenital heart disease in Saudi Arabia.AmJ Med Genet 2001; 99:8-13.

7. Blomberg MI and Kallen B. Maternal obesity and morbid obesity: the risk for birth defects in the offspring. Birth Defects Res A Clin Mol Teratol 2010; 88:35-40.

8. Botto LD, Mulinare J, and Erickson JD. Do multivitamin or folic acid supplements reduce the risk for congenital heart defects Evidence and gaps. Am J Med Genet 2003; 121:95-110.

9. Caton AR, Bell EM, Druschel CM, Werler MM, Lin AE, Browne ML, McNutt LA, Romitti PA, Mitchell AA, Olney RS and Correa A. Antihypertensive medication use during pregnancy and the risk of cardiovascular malformations 2009; 54:63-70.

10. CDC,(2016) congenital heart diseases(CHDs) https://www.cdc.gov/ncbddd/heartdefects/atrialseptaldefect.html Accessed at 19/1/2017.

11. Elizabeth D Agabegi; Agabegi, Steven S. (2008). Step-Up to Medicine (Step-Up Series). Hagerstown, MD: Lippincott Williams \& Wilkins. ISBN 0-7817-7153-6.

12. Faheem Ul Haq, Fatima Jalil, Saman Hashmi, Maliha Iqbal Jumani, Aamer Imdad, Mehnaz Jabeen, Javad Tauseef Hashmi, Furqan Bin Irfan, Muhammad Imran, and Mehnaz Atiq Risk factors predisposing to congenital heart defects Ann Pediatr Cardiol. 2011; 4(2): 117-121.

13. Hoffman JI, Kaplan S, Liberthson RR, Prevalence of congenital heart disease. American Heart Journal 2004; 147 425-39.

14. Jenkins KJ, Correa A, Feinstein JA, Botto L, Britt AE, Daniels SR, Elixson M, Warnes CA and Webb CL, American Heart Association Council on Cardiovascular Disease in the $\mathrm{Y}$ : Noninherited risk factors and congenital cardiovascular defects: current knowledge: a scientific statement from the American Heart Association Council on Cardiovascular Disease in the Young: endorsed by the American Academy of Pediatrics. Circulation 2007; 115:2995-3014.

15. Khalid Y, Mumtaz G, Bitar F, Chamseddine F, Kassar M. Rashidi J, Makhoul G, and Tamim H. Consanguineous Marriage and Congenital Heart Defects For the National Collaborative Perinatal Neonatal Network (NCPNN-- American Journal of Medical Genetics Part A 2006; 140A:1524-1530.

16. Mazen I, Amin H, Kamal A and El Ruby M. "Homozygous Mutation of the FGFR1 Gene AssociatedWith Congenital Heart Diseases and 46 XY Disorder of Sex Development" Departments of Clinical Genetics, Medical Molecular, Human Cytogenetics and National Research Center in Cairo Egypt 2016; 10: 16-22.

17. Tandon A, Sengupta S, Shukla V and Danda_S. Curr. Res. J. Biol. Sci., 2010, 2(4): 253-258.

18. Webb GD, Smallhorn JF, Therrien J, and Redington AN. Congenital heart disease. In: Bonow RO, Man DL, Zipes DP, Libby P, eds. Braunwald's Heart Disease: A Textbook of Cardiovascular Medicine Philadelphia, Pa: Saunders Elsevier; 2011; 9:714-833. 